\title{
Place Matters: Revealing Infectious Disease Disparities Using Area-Based Poverty
}

\author{
Kimberly Yousey-Hindes ${ }^{\star 1}$, Sharon K. Greene ${ }^{2}$, Kelley Bemis ${ }^{3}$ and Kristen Soto ${ }^{4}$ \\ 'Emerging Infections Program, Yale School of Public Health, New Haven, CT, USA; ${ }^{2}$ New York City Department of Health and Mental \\ Hygiene, Queens, NY, USA; ${ }^{3}$ Cook County Department of Public Health, Forest Park, IL, USA; ${ }^{4}$ Connecticut Department of Public \\ Health, Hartford, CT, USA
}

\section{Objective}

The panel will describe applying the methods of Harvard's Public Health Disparities Geocoding Project ${ }^{1}$ to a diverse collection of infectious disease surveillance data from 14 US states and New York City. This session will demonstrate the feasibility and utility of using US Census data to reveal sub-populations vulnerable to infectious diseases.

\section{Introduction}

Most public health surveillance systems in the United States do not capture individual-level measures of socioeconomic position. Without this information, socioeconomic disparities in health outcomes can be hidden. However, US Census data can be used to describe neighborhood-level socioeconomic conditions like poverty and crowding. Place matters. Neighborhood affects health independently of personal characteristics. Thus, important trends may be elucidated by linking geocoded public health surveillance data to area-based measures of socioeconomic position, such as the percentage of residents with incomes below the federal poverty level.

\section{Description}

Panel members will each share their experience using the methods of the Public Health Disparities Geocoding Project on an infectious disease surveillance dataset. Topics covered will include:

- Working with US Census data, both decennial population files and American Community Survey estimates

- Accessing online methodological resources from the Council of State and Territorial Epidemiologists and the Public Health Disparities Geocoding Project at Harvard School of Public Health

- Identifying health department resources needed to complete similar analyses

- Establishing interdepartmental partnerships to carry out specialized methods (e.g., geocoding)

- Consulting subject matter experts to interpret results

- Communicating findings for use in public health policy and action Specifically, the audience will hear from three epidemiologists who conducted similar independent analyses. The discussion will include successes and challenges in analyzing the incidence of 53 reportable communicable diseases by census tract-level poverty in New York City, an area of pronounced income inequality ${ }^{2}$. From Connecticut, analysis of reported Campylobacter infections from 1999-2009 will highlight the ability of this methodology to detect socioeconomic disparities within sub-groups and include interpretation of unexpected results. Finally, discussion of the analysis of influenza hospitalization data from over 70 counties in 14 states will help to illustrate the obstacles to and ultimate value of sharing data across jurisdictions. Audience members will learn how to conduct similar analyses with their own data and where to find detailed guidance.

\section{Audience Engagement}

Audience members will be asked to discuss barriers to implementing routine analysis of surveillance data within their own jurisdictions according to area-based poverty. Technical as well as conceptual questions will be answered. Audience recommendations for acting on the results of similar analyses in terms of policy and prevention measures to advance health equity will be encouraged.

\section{Keywords}

Health Disparities; Geospatial analysis; Poverty; Socioeconomic Status; Geocoding

\section{Acknowledgments}

The authors wish to acknowledge and thank Dr. Nancy Krieger and Dr. James Hadler for their inspiration and guidance.

\section{References}

1. Krieger N, Chen JT, Waterman PD, Rehkopf DH, Subramanian SV. Painting a truer picture of US socioeconomic and racial/ethnic health inequalities: The Public Health Disparities Geocoding Project. Am J Public Health 2005; 95: 312-323. doi:10.2105/AJPH.2003.032482.

2. Greene SK, Levin-Rector A, Hadler JL, Fine AD. Disparities in reportable communicable disease incidence by census tractlevel poverty, New York City, 2006-2013. Am J Public Health, 2015;105(9):e27-34. doi:10.2105/AJPH.2015.302741.

\section{*Kimberly Yousey-Hindes}

E-mail: kimberly.yousey-hindes@yale.edu 